EPJ Web of Conferences 75, 04004 (2014)

DOI: $10.1051 /$ epjconf/ 20147504004

(C) Owned by the authors, published by EDP Sciences, 2014

\title{
MnZn-ferrites: Targeted Material Design for New Emerging Application Products
}

\author{
V. T. Zaspalis ${ }^{1,2, a}$, V. Tsakaloudi ${ }^{2}$, and G. Kogias ${ }^{1,2}$ \\ ${ }^{1}$ AristotleUniversity of Thessaloniki, Department of Chemical Engineering, Laboratory of Materials Technology, \\ 54124 Thessaloniki, Greece \\ ${ }^{2}$ Center for Research and Technology-Hellas, Chemical Process and Energy Resources Institute, Laboratory of \\ Inorganic Materials, 57001 Thessaloniki, Greece
}

\begin{abstract}
In this article the main characteristics for emerging MnZn-ferrite applications are described on the basis of the new demands they possess on the ferrite material development. A number of recently developed $\mathrm{MnZn-ferrite}$ materials is presented together with the main scientific principles lying behind their development. These include: (i) high saturation flux density MnZn-ferrites (i.e. $\mathrm{B}_{\text {sat }}=550 \mathrm{mT}$ at $10 \mathrm{kHz}, 1200 \mathrm{~A} / \mathrm{m}, 100^{\circ} \mathrm{C}$ ), (ii) low power losses $\mathrm{MnZn}$-ferrites (i.e. $\mathrm{P}_{\mathrm{v}} \sim 210 \mathrm{~mW} \mathrm{~cm}^{-3}$ at $100 \mathrm{kHz}, 200 \mathrm{mT}, 100^{\circ} \mathrm{C}$ ), (iii) $\mathrm{MnZn}$-ferrites with broad temperature stability (i.e. $\mathrm{P}_{\mathrm{V}}<375 \mathrm{~mW} \mathrm{~cm}{ }^{-3}$ for $25^{\circ} \mathrm{C}<\mathrm{T}<140^{\circ} \mathrm{C}$ at $100 \mathrm{kHz}, 200 \mathrm{mT}$ ), and (iv) MnZnferrites with high and frequency stable permeability (i.e. $\mu_{\mathrm{i}} \sim 12600$ at $10 \mathrm{kHz}, 0.1 \mathrm{mT}, 25^{\circ} \mathrm{C}$ and $\tan (\delta) / \mu_{\mathrm{i}}=20.5 \times 10^{-6}$ at $\left.100 \mathrm{kHz}\right)$. In a final discussion the importance of defect chemistry for the time stability and stress sensitivity of the magnetic properties is discussed and some important issues are addressed, encountered during the transfer of a laboratory developed material to a large scale industrial production process.
\end{abstract}

\section{Introduction}

$\mathrm{MnZn-ferrites} \mathrm{is} \mathrm{the} \mathrm{class} \mathrm{of} \mathrm{soft} \mathrm{magnetic} \mathrm{materials} \mathrm{with}$ the widest range of technological applications [1,2]. They are used in magnetic components that, basically, perform inductive, transforming or absorbing functions and can be found almost in all electric, electronic or telecommunication equipment.

Although the fundamental principles of antiferromagnetism / ferrimagnetism have been outlined several decades ago [3, 4], new MnZn-ferrite materials are being continuously developed in order to meet the continuously evolving demands of new applications. The differentiation between all these materials lies, on one hand, on the absolute values of important magnetic properties such as saturation flux density, relative magnetic permeability, power losses or Neel temperature, on the other hand, on their temperature, frequency or magnetic field dependence.

In this article, some new application examples are described with emphasis on the ferrite material requirements and the basic principles along which new materials have been developed. Finally, some issues will be addressed in relation to property stability and the transfer of laboratory developed materials to large scale industrial production.

\section{High Saturation Flux Density MnZn- Ferrites}

Wireless battery charging, especially in situations where significant power is involved, is projected as a very promising concept in future auto motion. Moreover, new and more efficient motor designs employ stators constructed of ceramic magnetic materials. These emerging applications require $\mathrm{MnZn}$-ferrite materials with saturation flux densities quite higher than the 390$400 \mathrm{mT}\left(\mathrm{T}=100^{\circ} \mathrm{C}, \mathrm{H}=1200 \mathrm{~A} / \mathrm{m}\right)$ exhibited by existing materials. In addition, the power losses should not exceed $1000 \mathrm{~mW} \mathrm{~cm}{ }^{-3}$ (at $100 \mathrm{kHz}, 200 \mathrm{mT}, 100^{\circ} \mathrm{C}$ ) and an appreciable magnetic permeability $\left(\mu_{\mathrm{i}} \sim 1000\right)$ should still remain in the material.

\subsection{Iron Excess}

The saturation flux density $\left(\mathrm{B}_{\mathrm{s}}\right)$ of a ferrimagnetic material with cubic spinel structure is, as well known, reflected by the difference of the saturation flux densities of the two sublattices. In that sense, iron oxide excess $\delta$ in the mixed oxide $x \mathrm{ZnO}+(1-x) \mathrm{MnO}+(1+\delta) \mathrm{Fe}_{2} \mathrm{O}_{3}$ is expected to increase the saturation flux density, provided

${ }^{a}$ Corresponding author : zaspalis@auth.gr

This is an Open Access article distributed under the terms of the Creative Commons Attribution License 2.0, which permits unrestricted use, distribution, and reproduction in any medium, provided the original work is properly cited. 
that the excess iron $\mathrm{Fe}^{3+}$ is reduced to $\mathrm{Fe}^{2+}$ and is preferentially located on A-sublattice sites.

In figure 1 the saturation flux density is shown as a function of iron excess for MnZn-ferrites with an optimized $\mathrm{Mn} / \mathrm{Zn}$ ratio of $\sim 1.1$ (i.e.).

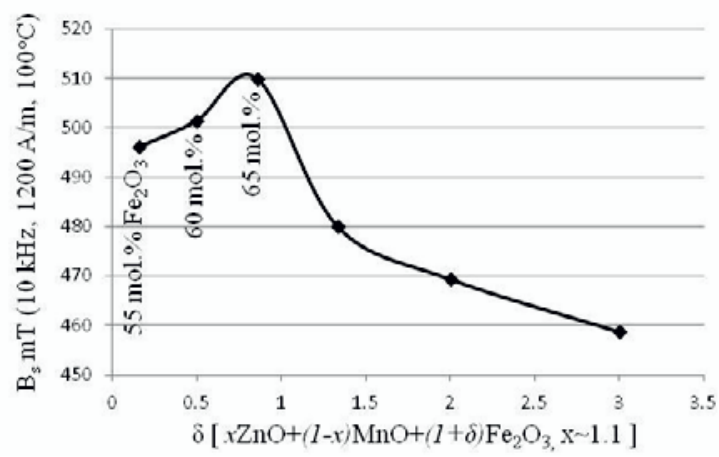

Fig. 1.Saturation flux density $\left(\right.$ at $\left.100^{\circ} \mathrm{C}\right)$ as a function of iron excess in $\mathrm{MnZn}$-ferrites with $\mathrm{Mn} / \mathrm{Zn}$ ratio 1.1 .

As indicated in figure 1 , an iron oxide excess up to 65 mol. $\%(\delta \sim 0.86)$ results to an increase of the saturation flux density. Higher excess results to a decrease.

The reason for the existence of this optimum has been clarified by morphological investigation of the samples, where it appeared that even after firing in reducing atmospheres, at high iron contents, certain amounts of hematite $\left(\mathrm{Fe}_{2} \mathrm{O}_{3}\right)$ and magnetite $\left(\mathrm{Fe}_{3} \mathrm{O}_{4}\right)$ still exist in the samples. The solubility limits have been probably reached or exceeded. This is illustrated in the typical Xray diffraction patterns shown in figure 2 .

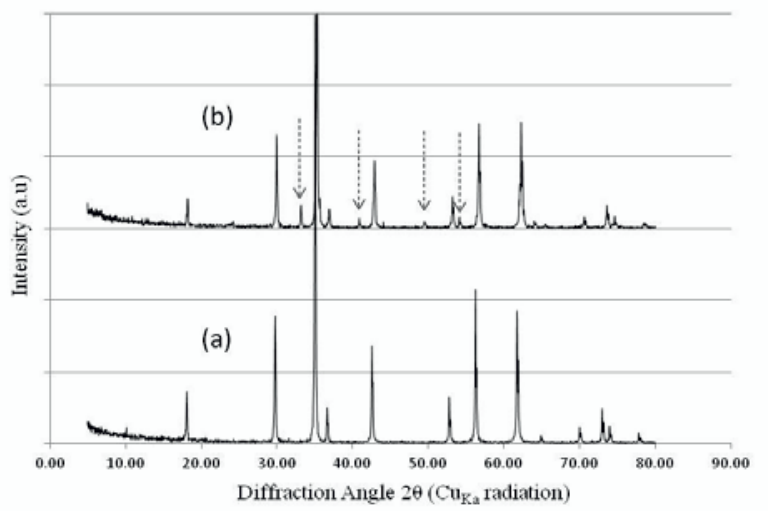

Fig. 2. (a) Typical X-ray pattern exhibited by samples with iron oxide contents up to $65 \mathrm{~mol} \% \%$ where only the spinel phase could be detected. (b) Typical X-ray pattern exhibited by samples with higher iron oxide contents where besides the main spinel phase also other phases such as $\mathrm{Fe}_{2} \mathrm{O}_{3}$ and $\mathrm{Fe}_{3} \mathrm{O}_{4}$ could be detected.

\subsection{Addition of $\mathrm{NiO}$}

Although iron excess results to an appreciable increase of the saturation flux density, this is not considered enough for the wireless charging applications mentioned earlier. Additional increase of the saturation flux density can be achieved by the addition of $\mathrm{NiO}$ at contents of $1-3 \mathrm{wt} . \%$ [5]. The selection of $\mathrm{NiO}$ is based on considerations that are qualitatively shown in figure 3.

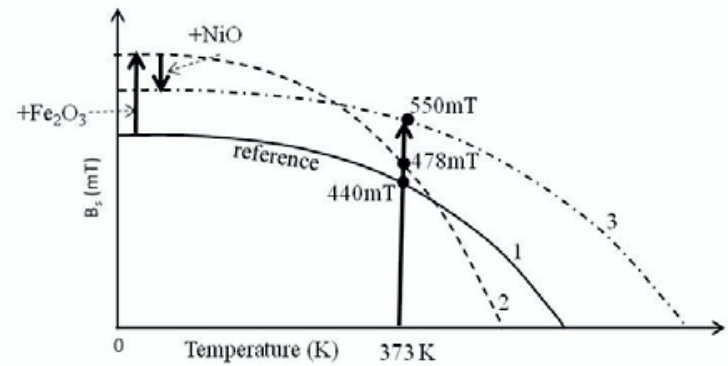

Fig. 3. Schematic drawing on the effect of $\mathrm{NiO}$ additions on the saturation flux density of MnZn-ferrites.

The earlier mentioned estimation of the saturation flux density based on sublattice considerations is valid at very low temperatures. As well known, the saturation flux density decreases with temperature up to the Neel temperature where it becomes zero. In MnZn-ferrites there is an inverse proportionality between the low temperature saturation flux density and the Neel temperature. The addition of $\mathrm{Fe}_{2} \mathrm{O}_{3}$ in the reference specimen (line 1 in figure 3 ) might have resulted to a substantial increase of the difference of the magnetization between the two sublattices. However, also the temperature sensitivity of the saturation flux density became higher (line 2 in figure 3 ) so that not much of the gain has been left over at the temperature which is of interest for the application and specified as standard $\left(100^{\circ} \mathrm{C}\right)$.

NiZn-ferrites are well known materials that differ from $\mathrm{MnZn-ferrites,} \mathrm{among} \mathrm{others,} \mathrm{because} \mathrm{they} \mathrm{exhibit}$ quite lower saturation flux densities but (because of that) significantly higher temperature stabilities and higher Neel temperatures. The addition of small amounts of $\mathrm{NiO}$ in a MnZn-ferrite might then decrease the low temperature saturation flux density but, because of the parallel temperature stability increase, may result to materials that at $100^{\circ} \mathrm{C}$ exhibit higher saturation flux densities (line 3 in figure 3 ). The experimental results indeed showed that the incorporation of $\mathrm{NiO}$ in iron excess MnZn-ferrites results to even higher saturation flux densities, as can be also concluded by comparing the results of Table 1 with those of figure 1 .

Along the main guidelines described in paragraphs 2.1 and 2.2 a new polycrystalline MnZn-ferrite material has been synthesized by the conventional ceramic method (solid state oxide method [6]), the properties of which are summarized in Table 1 [5]. The material is suitable for wireless power charging applications and fulfils all set specifications.

\section{Low Loss MnZn-ferrites}

Low frequency (i.e. up to $400 \mathrm{kHz}$ ) MnZn-ferrites aimed to be used as power transformers are being traditionally specified at two very distinct conditions i.e. at $100 \mathrm{kHz}$, $200 \mathrm{mT}$ as well as at $500 \mathrm{kHz}, 50 \mathrm{mT}$. The reasons are quite unclear and are probably related to the market structure. It is, however, very clear that these simultaneous specifications impose complications and limitations to the ferrite material development. 
Table 1.Magnetic properties of developed high saturation flux density MnZn-ferrite.

\begin{tabular}{|c|c|}
\hline $\begin{array}{c}\text { Property } \\
\text { (measurement conditions) }\end{array}$ & Value \\
\hline $\begin{array}{c}\text { Initial permeability }\left(\mu_{\mathrm{i}}\right) \\
\left(\mathrm{f}=10 \mathrm{kHz}, \mathrm{B}=0.1 \mathrm{mT}, \mathrm{T}=25^{\circ} \mathrm{C}\right)\end{array}$ & 1020 \\
\hline $\begin{array}{c}\text { Power losses }\left(\mathrm{P}_{\mathrm{v}}\right) \\
\left(\mathrm{f}=100 \mathrm{kHz}, \mathrm{B}=200 \mathrm{mT}, \mathrm{T}=25^{\circ} \mathrm{C}\right)\end{array}$ & $1500 \mathrm{~mW} \mathrm{~cm}^{-3}$ \\
\hline $\begin{array}{c}\text { Power losses }\left(\mathrm{P}_{\mathrm{v}}\right) \\
\left(\mathrm{f}=100 \mathrm{kHz}, \mathrm{B}=200 \mathrm{mT}, \mathrm{T}=100^{\circ} \mathrm{C}\right)\end{array}$ & $800 \mathrm{~mW} \mathrm{~cm}^{-3}$ \\
\hline $\begin{array}{c}\text { Power losses }\left(\mathrm{P}_{\mathrm{v}}\right) \\
\left(\mathrm{f}=10 \mathrm{kHz}, \mathrm{B}=400 \mathrm{mT}, \mathrm{T}=25^{\circ} \mathrm{C}\right)\end{array}$ & $350 \mathrm{~mW} \mathrm{~cm}^{-3}$ \\
\hline $\begin{array}{c}\text { Power losses }\left(\mathrm{P}_{\mathrm{v}}\right) \\
\left(\mathrm{f}=10 \mathrm{kHz}, \mathrm{B}=400 \mathrm{mT}, \mathrm{T}=100^{\circ} \mathrm{C}\right)\end{array}$ & $275 \mathrm{~mW} \mathrm{~cm}^{-3}$ \\
\hline $\begin{array}{c}\mathrm{Saturation} \text { flux density }\left(\mathrm{B}_{\mathrm{s}}\right) \\
\left(10 \mathrm{kHz}, \mathrm{H}=1200 \mathrm{~A} / \mathrm{m}, \mathrm{T}=25^{\circ} \mathrm{C}\right)\end{array}$ & $642 \mathrm{mT}^{\circ}$ \\
\hline $\begin{array}{c}\mathrm{Saturation} \text { flux density }\left(\mathrm{B}_{\mathrm{s}}\right) \\
\left(10 \mathrm{kHz}, \mathrm{H}=1200 \mathrm{~A} / \mathrm{m}, \mathrm{T}=100^{\circ} \mathrm{C}\right)\end{array}$ & $550 \mathrm{mT}$ \\
\hline
\end{tabular}

In the low frequency $(100 \mathrm{kHz})$ region the magnetic losses are dominated by the hysteresis losses. In order to minimize this type of losses, relatively large $(\sim 10 \mu \mathrm{m})$ and pure or defect- and inclusion-free grains are preferred. The specific resistivity is not of crucial importance and the deposition of isolating phases along the grain boundaries is optional and depends on the desired permeability values.

In the higher frequency region $(500 \mathrm{kHz})$ the eddy current losses cannot be considered of minor importance since they play a dominant role in the determination of the total power losses of the components. Eddy current losses depend on the specific resistivity of the polycrystalline component. Their minimization requires materials with a high specific resistivity which in turn means small grains (e.g. large grain boundary "concentrations") and grain boundaries with a high specific resistivity. The latter is usually accomplished through the deposition of isolating glassy phases along the grain boundaries. Both measures diminish the magnetic permeability.

With those mentioned in the previous two paragraphs in mind, currently existing ferrite materials specified for the application region $100-500 \mathrm{kHz}$, consist an optimum compromise, since they try to meet good magnetic performance over a frequency region where the microstructural requirements are entirely different. In figure 4 (line 1), the power losses $(100 \mathrm{kHz}, 200 \mathrm{mT})$ as a function of temperature are shown for a state of the art $\mathrm{MnZn}$-ferrite. As can be seen the power loss minimum occurs at $100^{\circ} \mathrm{C}$ and approaches $275 \mathrm{~mW} \mathrm{~cm}^{-3}$. The initial magnetic permeability is about 2250 (measurement conditions are shown in the figure).

Emerging mass consumption applications such as the magnetic components used for the construction of inverter units that follow almost all renewable energy production sources, do not require the higher frequency specifications, but they do require low power losses at low frequencies. This gives freedom to the materials development engineer to optimize the microstructure according only to the low frequency design criteria, mentioned earlier, without paying too much attention on the strict specific resistivity requirements. The result is shown in figure 4 (line 2) where it is indicated that power losses can be reduced from $\sim 275$ down to $\sim 210 \mathrm{~mW} \mathrm{~cm}^{-3}$.

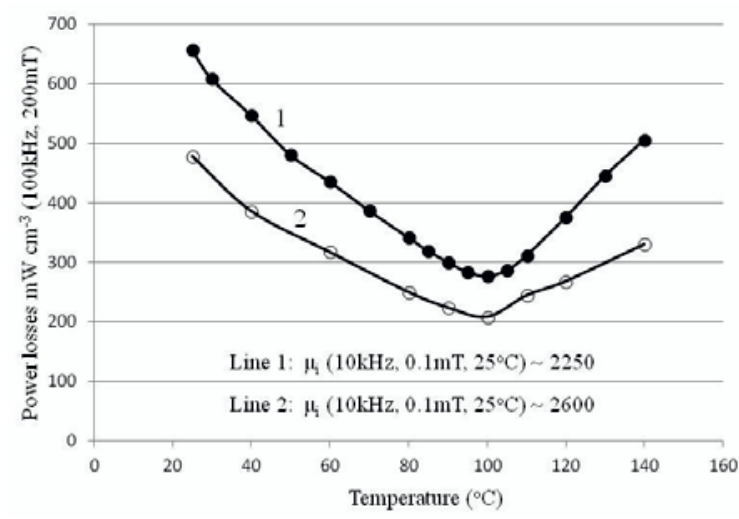

Fig. 4. Power losses as a function of temperature for reference (line 1) and recently developed (line 2) MnZn-ferrites.

An additional positive, but expected, result is the simultaneous increase of the initial permeability by approximately $15 \%$ due to the deterioration of the specific resistivity of the polycrystalline material and the slight increase of the average grain size.

\section{Broad Temperature Range MnZn- ferrites}

The MnZn-ferrite materials whose properties are shown in figure 4 are optimized for operation at a steady state temperature of $100^{\circ} \mathrm{C}$. The temperature dependency of the power losses is quite sharp and if the material is at temperatures outside the optimum region the operation is energetically quite inefficient. A relatively recent trend in the application market of magnetic components (particularly in the automobile industry), probably triggered by the general tendency towards efficient energy utilization, asks for the development of magnetic materials with low losses over broad temperature ranges (i.e. from 25 up to $\sim 140^{\circ} \mathrm{C}$ ), [7]. This trend has become obvious both in the low $(\sim 100 \mathrm{kHz})$ as well in the higher $(\sim 500 \mathrm{kHz})$ frequency region.

The general concept for approaching the problem is for both cases the same. It is well known that, in MnZnferrites used for power applications, the power loss vs. temperature curve is qualitatively similar with the magnetocrystalline anisotropy constant vs. temperature curve. In addition, the temperature of the power loss minimum, coincides with the temperature at which the anisotropy constant becomes zero (i.e. there is no anisotropy field opposing the movement of the magnetic dipoles). At temperatures below or above this temperature the magnetocrystalline anisotropy takes positive or negative values.

In order to change the temperature dependency of the anisotropy constant of the host lattice, certain ions should be added that posses opposite sign anisotropy and with their introduction will compensate the already existing lattice anisotropy. Such an ion is $\mathrm{Co}^{2+}$, which is added to the MnZn-ferrite at amounts in the order of a few thousand ppm. The results are shown in figure 5 . 


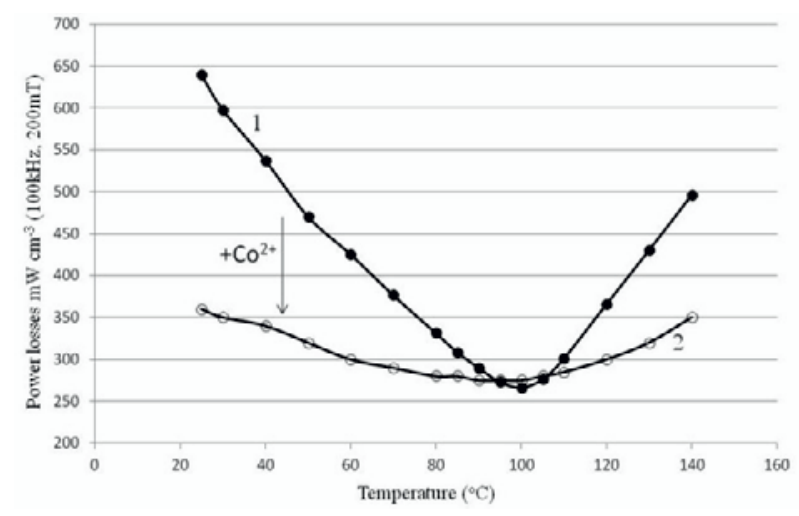

Fig. 5. The effect of $\mathrm{Co}^{2+}$ addition on the temperature dependency of the power losses of MnZn-ferrites.

As shown in figure 5 the Cobalt doped sample (line 2) exhibits a much lower power loss dependency with temperature when compared to the undoped sample (line 1). It is worth mentioning that as long as the temperature of $100^{\circ} \mathrm{C}$ concerns, the undoped sample continuous to show superior performance. This is generally true for all temperatures: the materials optimized for a specific temperature are, at this temperature, always better than broad temperature materials.

\section{High Frequency Stability MnZn-ferrites}

Nowadays electronic and telecommunication devices are expected to process at the same time continuously increasing amount of information. Unavoidably, the operation frequencies have to increase. For magnetic components such as MnZn-ferrites, this means that the frequency stability of the magnetic permeability becomes of major importance. Expressed differently, it is important to know the frequency at which the losses become appreciable and cause reduction of the magnetic permeability.

For a given high permeability composition such as $\left(\mathrm{Mn}_{0.5} \mathrm{Zn}_{0.5}\right) \mathrm{Fe}_{2+\delta} \mathrm{O}_{4}$, the achievement of a high initial permeability proceeds through the achievement of large and pore free grains.This is being realized through the utilization of sintering schedules with prolonged times at high temperatures and high oxygen partial pressures. The frequency stability of the permeability depends on the specific resistivity of the polycrystalline structure and in particular on the d.c. resistivity of the grain boundaries. These are modified through the usage of dopants that accumulate along the grain boundaries raising their resistivity.

During the final firing step of compacted MnZnferrite specimens several processes take place such as densification, sintering or dopant diffusion. Although clearly distinct from one another, they may take place in parallel, especially at the high temperature stages.

High grain boundary resistivities and therefore high frequency stabilities can be achieved if during the firing step, after having reached sufficient density and grain size, time is provided for dopant diffusion and accumulation along the grain boundaries [8]. This can be done by integrating constant temperature plateaus during the cooling stage of the firing cycle. A typical firing schedule for high permeability, high frequency MnZnferrites is shown in figure 6 . As it can be seen, the top temperature is set at $1380^{\circ} \mathrm{C}$, while upon cooling there is plateau at $1200^{\circ} \mathrm{C}$ with a duration of 3 hours, which serves for the necessary resistivity increase of the material. In Table 2 the typical material properties are shown.

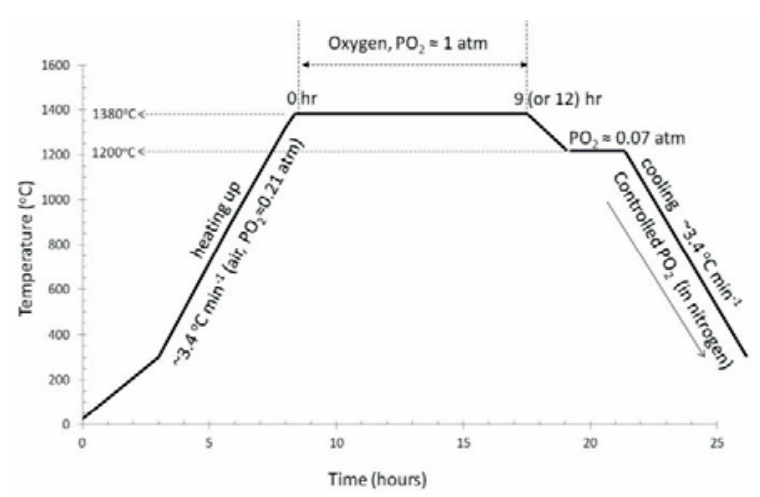

Fig. 6. Typical firing schedule of a high permeability high frequency stability MnZn-ferrite $\left[\left(\mathrm{Mn}_{0.5} \mathrm{Zn}_{0.5}\right) \mathrm{Fe}_{2+\delta} \mathrm{O}_{4}\right]$.

Table 2.Properties of high permeability and frequency stable $\mathrm{MnZn-ferrite} \mathrm{materials.}$

\begin{tabular}{|c|c|}
\hline $\begin{array}{c}\text { Property } \\
\text { (measurement conditions) }\end{array}$ & Value \\
\hline $\begin{array}{c}\text { Initial permeability }\left(\mu_{\mathrm{i}}\right) \\
\left(\mathrm{f}=10 \mathrm{kHz}, \mathrm{B}=0.1 \mathrm{mT}, \mathrm{T}=25^{\circ} \mathrm{C}\right)\end{array}$ & 12600 \\
\hline Loss factor: $\frac{\tan (\delta}{\mu} \times 0^{-}$ & 3.1 \\
$\left(\mathrm{f}=10 \mathrm{kHz}, \mathrm{B}=0.1 \mathrm{mT}, \mathrm{T}=25^{\circ} \mathrm{C}\right)$ & \\
\hline Loss factor: $\frac{\tan (\delta}{\mu} \times 0^{-}$ & 20.5 \\
$\left(\mathrm{f}=100 \mathrm{kHz}, \mathrm{B}=0.1 \mathrm{mT}, \mathrm{T}=25^{\circ} \mathrm{C}\right)$ & \\
\hline
\end{tabular}

\section{Defect Chemistry - Stability of MnZn- ferrites}

Defect chemistry and in particular, concentrations of point defects, have been found to play an important role in determining the behaviour of MnZn-ferrites and in particular properties such as time stability (dissacomodation) and stress sensitivity of magnetic properties.

The great majority of MnZn-ferrites used nowadays are iron excess and refer to compositions of the type $x \mathrm{ZnO}+(1-x) \mathrm{MnO}+(1+\delta) \mathrm{Fe}_{2} \mathrm{O}_{3} \quad$ where $\delta>0 \quad$ (small exceptions are some materials for absorption applications which are not included in this discussion). Their defect structure can be reasonably well understood by a simple defect model, according to which the excess $\mathrm{Fe}^{3+}$ occupies divalent A-sites creating therefore $(\delta /(3 \delta+4)$ per unit cell)negatively charged cation vacancies for charge compensation. The material becomes cation deficient. 
During the final firing, the partial pressure of oxygen is regulated so that a number of the $\mathrm{Fe}^{3+}$ ions is reduced to $\mathrm{Fe}^{2+}$ according to the equation:

$2 \mathrm{Fe}^{3+}+\frac{3}{4} V_{A}^{\prime}+\mathrm{O}^{2-} \stackrel{K(T)}{\longleftrightarrow} 2 \mathrm{Fe}^{2+}+\frac{1}{2} \mathrm{O}_{2}(g)$

which is an equilibrium with constant $\mathrm{K}(\mathrm{T})$.

This reduction is essential for the magnetic performance of the material because it determines the $\mathrm{Fe}^{2+} / \mathrm{Fe}^{3+}$ ratio of the material, which dictates the magnetocrystalline anisotropy of the lattice.

However, as shown by equation (1), the concentration of cation vacancies is reduced in parallel with the reduction of $\mathrm{Fe}^{3+}$. It can be calculated that when $1 / 3$ of the iron excess $\delta$ is reduced, the material becomes exactly stoichiometric and the point defect concentrations are minimized. The oxygen partial pressure that corresponds to this reduction percentage according to equilibrium equation (1) is considered as optimum and depends not only on temperature but also on the main composition of the ferrite (i.e. on the total iron content). Lower oxygen partial pressure than this corresponding to stoichiometry will most probably result to anion deficient materials where the dominant type of point defects changes from cation to anion vacancies. The previous are schematically shown in figure 7.

As it has been repeatedly found in laboratory experiments, materials synthesized at this stoichiometric point possess the best stability of magnetic properties both as a function of time or as a function of some externally applied stress [9]. The explanation provided is that at this point the diffusion of cations (through cation vacancies) is limited. This diffusion of cations can be considered responsible either for disaccommodation or for the variation of magnetic properties upon the exertion of external stress (stress induced diffusion).

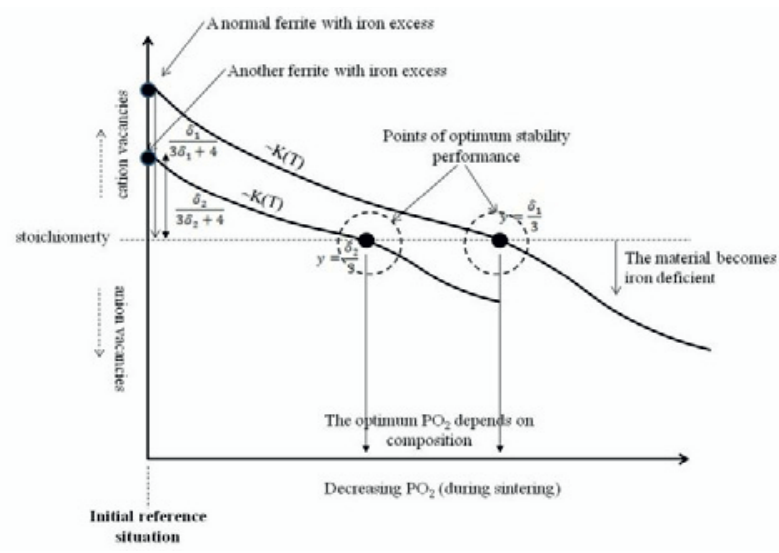

Fig. 7. Schematic presentation of the interaction between sintering partial pressure of oxygen and point defects in MnZnferrites.

The consequences of figure 7 on ferrite production technology are quite significant. Many restrictions imposed by figure 7 are in direct contradiction with other requirements on magnetic performance. For example, it is well known that the temperature of the power loss minimum (i.e. see figures 4,5 ) depends on the $\mathrm{Fe}^{2+} / \mathrm{Fe}^{3+}$ ratio. This ratio can be influenced (and the temperature of the minimum can be shifted) either by varying the oxygen partial pressure during sintering or by varying the total iron content of the composition. This implies that MnZn-ferrite materials can be synthesized with the power loss minimum temperature identical but with different total iron contents; the difference will be that the one with the higher iron content is sintered under higher partial pressure of oxygen. According to those said in this paragraph and qualitatively illustrated in figure 7 , those two materials, although with identical power loss behaviour, will not be the same and will differ in the stability of their magnetic performance with time or upon the exertion of externally applied stress.

\section{From Material Development to Industrial Production}

During laboratory material development the goal is the achievement of certain material properties. This is best served by synthesizing specimens of toroidal geometry and closed magnetic loops. Such configurations are free of demagnetization fields and allow the determination of the properties of the materials.

All magnetic properties of the specimens shown in this article (figures 1, 4, 5 and Table 1) refer to specimens of toroidal geometrywith an external diameter of $25 \mathrm{~mm}$, an internal diameter of $15 \mathrm{~mm}$ and a height of $5 \mathrm{~mm}$. They have been synthesized by the conventional ceramic process (mixed oxide process) which is the process by which the greatest majority of $\mathrm{MnZn}$-ferrites are being industrially produced.

The laboratory materials need, however, to be shaped into products of variable complex and large geometries that have to be suitable for a large scale production process at sufficient quality stability. This product geometry and shape change as well as the transfer into large volume unit operations may bring forward problems which are not obvious during the material development, that require additional research in order to face. Two representative case examples are illustrated below.

In general, all physical and chemical processes that occur in a specimen of certain small size during sintering, occur also in an identical specimen of different geometry. The main difference lies in the magnitude of the generated gradients due to resistances in mass and heat transfer that may in turn give rise to variable reaction rates etc. Gradients generate stresses. In a specimen of small geometry these stresses may not exceed the fracture strength of the material and are therefore of no significance and probably not noticeable in the magnetic performance. This is not the case in large geometry products where fracture strengths may be exceeded. The final result is, in most of the cases, the appearance of internal micro-cracks and certainly an inferior magnetic performance. An illustrative example is shown in figure 8 .

Textbook advice towards overcoming these problems dictates slower heating and cooling rates and in general slow process operation parameters. Unfortunately, an industrial production organization cannot afford the productivity loss and the increased production cost associated with low production rates. It is therefore 
necessary to find the route cause of the stress generating process and eliminate it. The difficulty is that any experiments in this direction cannot be executed in the laboratory and have to be carried out in real products under real processing conditions.

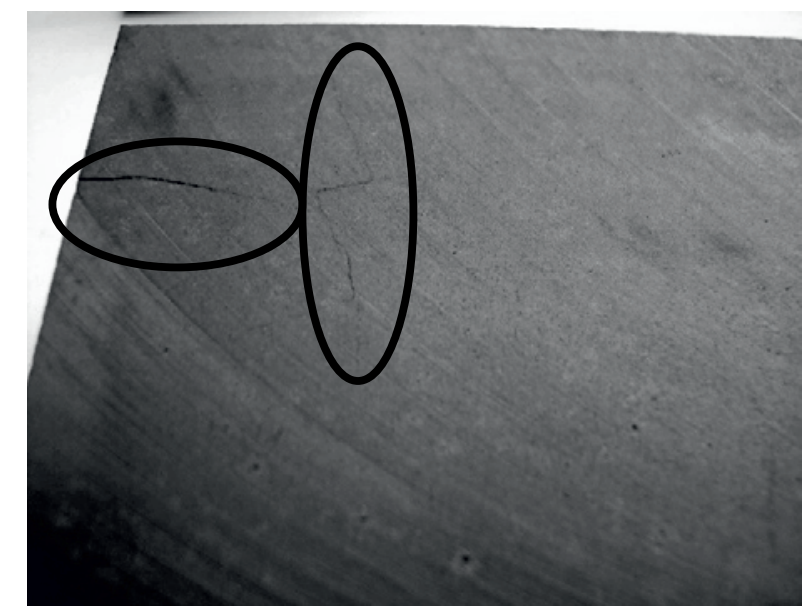

Fig. 8. Illustrations of internally generated microcracks in MnZn-ferrite products of large geometry.

As an example, the following can be mentioned. After prefiring of the raw material powder mixture $\mathrm{ZnO}$, $\mathrm{Mn}_{3} \mathrm{O}_{4}$ and $\mathrm{Fe}_{2} \mathrm{O}_{3}$, all possible intermediate phases may be formed (e.g. $\mathrm{ZnFe}_{2} \mathrm{O}_{4}, \mathrm{MnFe}_{2} \mathrm{O}_{4}, \mathrm{ZnMn}_{2} \mathrm{O}_{4}$ ), the relative amounts of which depend strongly on the morphology of the raw materials. As found, under conditions of coarse $\mathrm{Fe}_{2} \mathrm{O}_{3}$ and relatively fine $\mathrm{Mn}_{3} \mathrm{O}_{4}$ and $\mathrm{ZnO}$ the $\mathrm{ZnMn}_{2} \mathrm{O}_{4}$ formation dominates. This compound undergoes dissociation (to $\mathrm{ZnO}$ and $\mathrm{Mn}_{2} \mathrm{O}_{3}$ ) at temperatures around $900^{\circ} \mathrm{C}$ which is associated with significant volume expansion. In products of small geometry the stress generated by this volume expansion is probably lower than the fracture strength of the material. In large products, however, fracture limits are exceeded and cracks occur almost independent of the heating or cooling rates. The problem can be faced by eliminating the formation of $\mathrm{ZnMn}_{2} \mathrm{O}_{4}$ during prefiring. This can be done either by changing the raw material morphology (i.e. use a finer iron oxide) or by applying prefiring strategies that exclude the $\mathrm{ZnO}-\mathrm{Mn}_{3} \mathrm{O}_{4}$ reaction and the formation of $\mathrm{ZnMn}_{2} \mathrm{O}_{4}$.

Another example that illustrates the difference between laboratory and industrial practice is shown in figure 9.

In figure 9(a) a typical product stacking into an industrial stationary oven is shown. The products are stacked in columns, four products each. There are three levels of products into the oven, totally 12 layers. Each layer consists of 42 products.

Figure 9 refers to the sintering of high permeability $\mathrm{MnZn}$-ferrites and in particular to a material which when synthesized in the laboratory gives a relative initial permeability of 12500. In figures 9(b) and 9(c) the measured initial permeability levels are shown of all products of the top and bottom layer, in correlation to the coloured scale given in figure $9(\mathrm{~d})$. As it can be seen, there are significant deviations between the permeability

of the products within each layer, with the bottom layer being significantly inferior to the top layer.

(b)

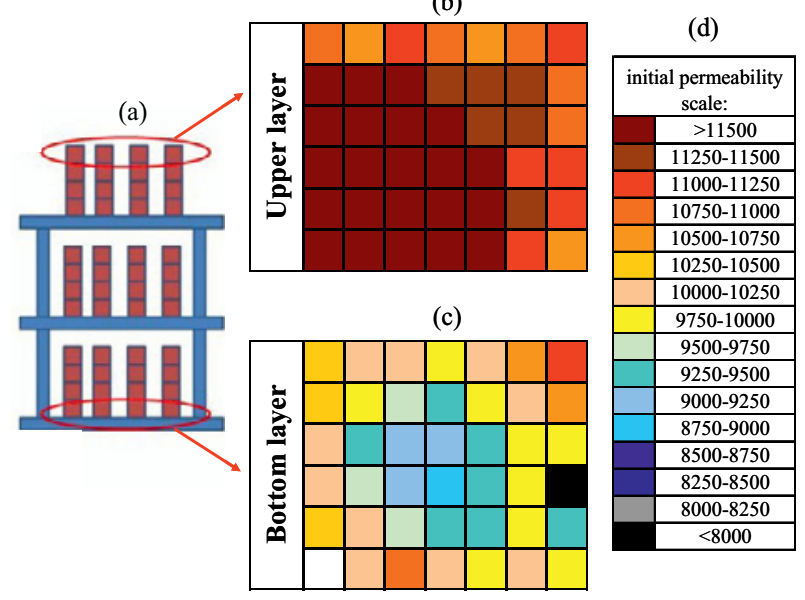

Fig. 9. Permeability mapping of products of the bottom and top layer of a typical product stacking in an industrial oven.

The physical phenomenon behind this permeability discrepancy is known and is related to $\mathrm{Zn}$ depletion described by the overall reaction:

$$
\mathrm{Zn}+\frac{1}{2} \mathrm{O}_{2}(\mathrm{~g}) \Leftrightarrow \mathrm{ZnO}(\mathrm{g})
$$

according to which $\mathrm{Zn}$ from the material reacts with the oxygen of the atmosphere towards the production of gaseous Zinc oxide. The rate of Zn "evaporation" from the material depends not only on the partial pressure of oxygen but also on the partial pressure of $\mathrm{ZnO}$ and thus on the rate of $\mathrm{ZnO}$ external removal. This means that the oxygen or air flow pattern around each product, as well as the nature and the distance of the supporting firebricks, where $\mathrm{ZnO}$ deposits, are important factors in determining the partial pressure of $\mathrm{ZnO}$ around each product [10].

In an industrial oven it is almost impossible to keep all these parameters identical for each product and the deviations in permeability are unavoidable. The problem is more pronounced in the manufacturing of high permeability MnZn-ferrites where prolonged heating times at almost pure oxygen atmospheres are used in order to achieve the required, for the high permeability, grain size. The ferrite production engineer needs to create innovative ideas in many directions such as oven and product configuration design or supporting material selection in order to keep the property deviations within economically acceptable limits.

\section{Conclusions}

The appearance of specific mass applications impose an even further differentiation on the development process of new ferrite materials which become more and more application dedicated.

In this context:

- High saturation flux density MnZn-ferrites have been developed with saturation of $642 \mathrm{mT}(\mathrm{f}=10 \mathrm{kHz}, \mathrm{H}=1200$ $\left.\mathrm{A} / \mathrm{m}, \mathrm{T}=25^{\circ} \mathrm{C}\right)$ and $550 \mathrm{mT}(\mathrm{f}=10 \mathrm{kHz}, \mathrm{H}=1200 \mathrm{~A} / \mathrm{m}$, 
$\left.\mathrm{T}=100^{\circ} \mathrm{C}\right)$ and power losses of $800 \mathrm{~mW} \mathrm{~cm}^{-3}(\mathrm{f}=100 \mathrm{kHz}$, $\mathrm{B}=200 \mathrm{mT}, \mathrm{T}=100^{\circ} \mathrm{C}$ )

- Low loss MnZn-ferrite materials for low frequency power applications have been developed with power losses of $\sim 210 \mathrm{~mW} \mathrm{~cm}^{-3} \quad(\mathrm{f}=100 \mathrm{kHz}, \mathrm{B}=200 \mathrm{mT}$, $\mathrm{T}=100^{\circ} \mathrm{C}$ )

- Wide temperature application range $\mathrm{MnZn}$-ferrite materials have been developed with losses lower than 400 $\mathrm{mW} \mathrm{cm} \mathrm{cm}^{-3}(\mathrm{f}=100 \mathrm{kHz}, \mathrm{B}=200 \mathrm{mT})$ over the entire temperature range from 25 to $140^{\circ} \mathrm{C}$

- High permeability MnZn-ferrites with high frequency stability of the permeability have been developed and in particular with $\mu_{\mathrm{i}} \sim 12600\left(\mathrm{f}=10 \mathrm{kHz}, \mathrm{B}=0.1 \mathrm{mT}, \mathrm{T}=25^{\circ} \mathrm{C}\right)$ and loss factor $\tan (\delta) / \mu_{\mathrm{i}}=20.5 \times 10^{-6}(\mathrm{f}=100 \mathrm{kHz}, \mathrm{B}=0.1$ $\mathrm{mT}, \mathrm{T}=25^{\circ} \mathrm{C}$ )

- The stability of the magnetic properties of MnZnferrites with time or upon the exertion of external stresses is, for iron excess materials, connected with the concentrations of point defects such as cation vacancies. As it appears from the results, minimization of the cation vacancies leads to materials with more stable magnetic performance.

- The successful (stable and reproducible) industrial production of a laboratory developed material is, in the case of MnZn-ferrites, very critical and may, very often, bring forward issues that are invisible during small scale processing and require additional research in order to be solved.

\section{References}

1. E. C. Snelling, Soft ferrites: properties and applications(Butterworth\&Co., UK, 1988)

2. A. Goldman, Handbook of modern ferrite technology (Kluwer Acad. Publ., US, 1999)

3. J. Smit, H. P. J. Wijn, Ferrites (Philips Technical Library, Eindhoven 1959)

4. A. Broese van Groenou, P.F. Bongers, A.L. Stuyts, Mater. Sci. Eng. 3, 317 (1968)

5. G. Kogias, D. Holz, V. Zaspalis, J. Jpn. Soc. Powder Powder Metall. (In Press, 2013)

6. J. Hanuszkiewicz, D. Holz, E. Eleftheriou, V. Zaspalis, J. Appl. Phys. 103, 103907 (2008)

7. K. Mori, K. Yasuhara, I. Nakahata, K. Nishikawa, J. Jpn. Soc. Powder Powder Metall. (In Press, 2013)

8. J. Kalarus, G. Kogias, D. Holz, V. Zaspalis, J. Magn. Magn. Mater. 324, 2788, (2012)

9. V. Tsakaloudi, D. Holz, V. Zaspalis, J. Mater. Sci. 48, 3825 (2013)

10. P. Sainamthip, V. R. W. Amarakoon, J. Am. Ceram. Soc. 71, 644 (1988) 